\title{
Oriental oculopalpebral dimensions: Quantitative comparison between Orientals from Japan and Brazil
}

\author{
Rodrigo U Takahagi' \\ Silvana A Schellini' \\ Carlos R Padovani' \\ Shinji Ideta ${ }^{2}$ \\ Nobutada Katori ${ }^{2}$ \\ Yasuhisa Nakamura ${ }^{2}$ \\ 'Department of Ophthalmology, \\ Faculdade de Medicina de Botucatu, \\ Botucatu, Sao Paulo State, Brazil; \\ ${ }^{2}$ Department of Oculoplastic and \\ Orbital Surgery, Hamamatsu Seirei \\ General Hospital, Hamamatsu, \\ Shizuoka-ken, Japan
}

\begin{abstract}
Objectives: Quantitative evaluation of palpebral dimensions of Japanese residents in Japan and Japanese descendant (Nikkeis) who live in Brazil, in order to define if environmental factors may influence these parameters.

Methods: A prospective study evaluating 107 Nikkeis from Brazil and 114 Japanese residents in Japan, aged 20 years or older. Exclusion criteria were those with palpebral position alterations, prior palpebral surgery, and crossbreeding. Images were obtained with a digital camera, $30 \mathrm{~cm}$ from the frontal plane at pupil height, with the individual in a primary position and the eye trained on the camera lens. Images were transferred to computer and processed by the Scion Image program. Measurements were made of distance between medial canthi, distance between pupils (IPD), superior eyelid crease position, distance between the superior lid margin and corneal reflexes (MRD), horizontal width, height, area, and obliquity of the palpebral fissure. Data were analyzed using analysis of variance for a three factor model and respective multiple comparison tests.

Results: Japanese residents and Nikkeis living in Brazil have similar measurements. Statistical differences were found for some age groups concerning distance between pupils, horizontal, and vertical fissures, palpebral fissure area, and obliquity with native Japanese presenting discretely higher measurements than Nikkeis.

Conclusion: Environmental factors do not affect palpebral dimensions of Nikkeis living in Brazil.

Keywords: eyelid dimensions, Japanese, Nikkeis, digital image
\end{abstract}

\section{Introduction}

Brazil is a country whose population consists of several different nationalities, among them the Japanese. They comprise the largest Nikkei community outside Japan. Japanese immigration occurred mainly from 1908 to 1935, and the large ethnic group living in Brazil has prevented crossbreeding. As a result, Japanese physical characteristics can be easily noted in Japanese descendants residing in Brazil.

Oriental eyelids have distinctive folds and contours that differentiate them from occidental eyelids due to inner anatomical relationships. The Oriental eyelid shows a narrower tarsal plate, a higher level of subcutaneous fat, and a higher level of fat posterior to the orbital septum than is found in Caucasian examples. The eyelid crease, when present, is located near the upper eyelid border due to the following anatomical features: the orbital septum fuses to the eyelid levator muscle aponeurosis at variable distances below superior tarsal border; the preaponeurotic fat protrusion and its thick feature blocks the attachments of the aponeurosis to orbicular muscle and skin next to the superior tarsal border; and the levator aponeurosis attaches to the orbicular muscle and skin next to the upper eyelid border (Doxanas and Anderson 1984; Jeong et al 1999). 
Studies have not been reported about eyelid measurements in the Japanese. In addition to this, there has been no comparison made between the eyelids measurement of native Japanese and Nikkeis living in other countries. There is no information available as to whether habits, climate condition, or the exposure to different environmental factors could induce variation in the eyelid and its contours. Could racial traits change under different living conditions?

This study was constructed in order to analyze, in a quantitative form, the measurements of eyelid contours in Japanese people living in Japan and in Nikkeis living in Brazil by using digital images.

\section{Materials and methods}

A prospective observational study was performed between August 2004 and July 2005, evaluating 107 Japanese descendents living in Brazil (São Paulo State), and 114 Japanese living in Japan (Hamamatsu). All of them were 20 years old or older. The studied populations were required to have resided in their respective countries since birth or for more than 60 years.

The protocol was approved by the Ethics Committee for Human Research at Botucatu School of Medicine (UNESP).

Exclusion criteria included those with systemic diseases that could cause changes in palpebral position, those with ocular or eyelid diseases, those who had undergone palpebral surgery, those who would not authorize photographic records, and crossbreeding individuals.

All images were taken by the same person using a digital camera (Nikon Coolpix 4100, China), with flash, positioned in the frontal plane parallel to and $30 \mathrm{~cm}$ from the facial plane, at pupil height with a metric scale stick on the face and looking at the camera lens. Images were transferred to a computer running Windows (Microsoft, Redmond, WA) and processed by Scion Image from the Scion Corporation (Frederick, MD).

The following dimensions were analyzed: distance between medial canthi, distance between pupils (IPD), superior palpebral crease position (at the central part of the superior eyelid), the distance between superior palpebral margin and corneal reflex (MRD), horizontal width, height, area, and obliquity of the palpebral fissure (Figure 1).

Data were analyzed by analysis of variance using a three factor model and respective multiple comparison tests.

\section{Results}

The distance between medial canthi tended to be larger in the Japanese than in Nikkeis, with men having significantly greater values than women in both groups. There were no differences when age groups were considered (Table 1).

The IPD tended to be larger in the Japanese, with men having larger IPD than women, and statistical difference for some age groups (Table 2).

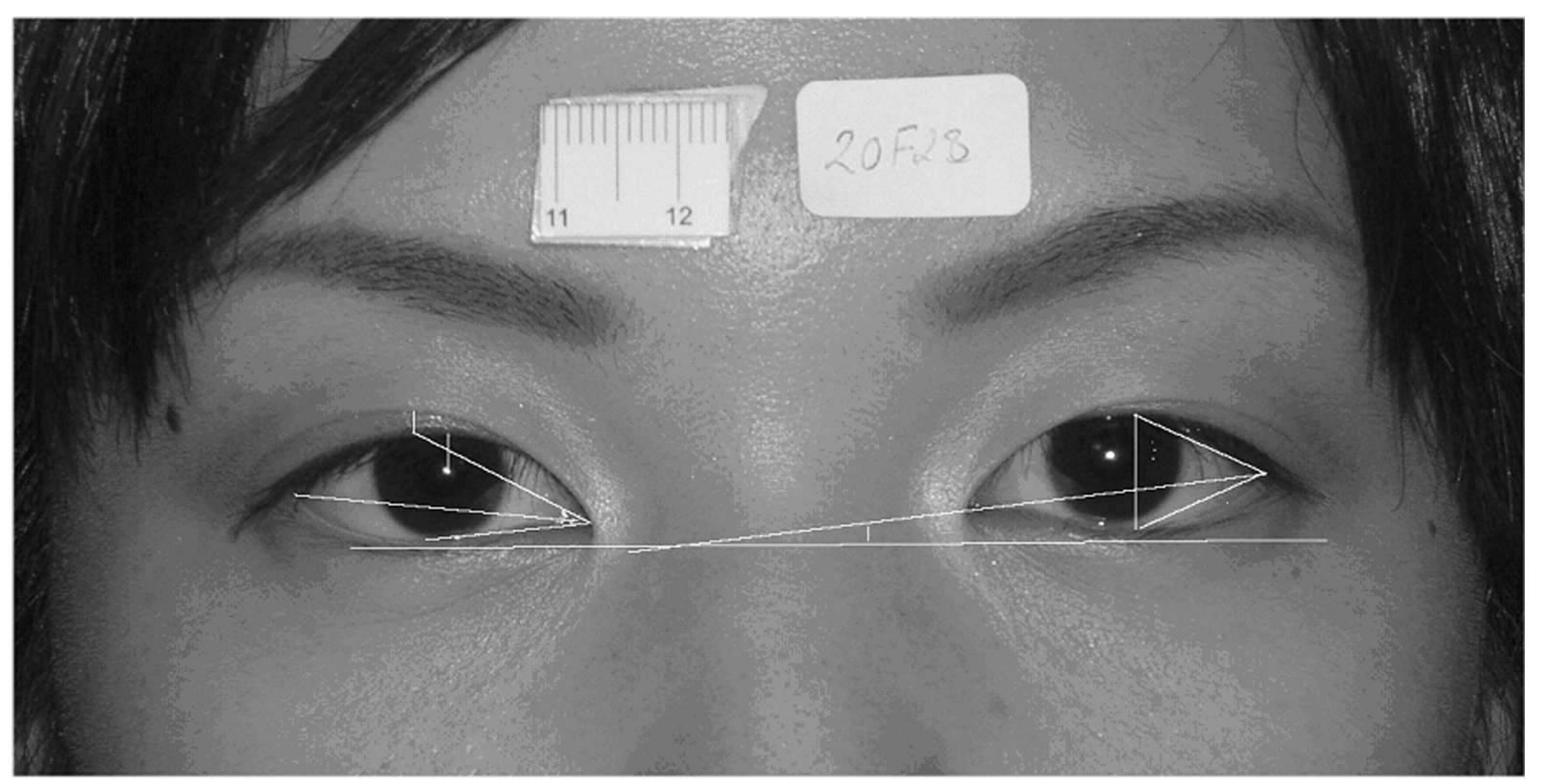

Figure I Measurements of oculopalpebral dimensions: inner distance, lateral canthus angle, medial canthus angle, palpebral fissure area, high and length, palpebral fissure obliquity, margin reflex distance, upper eyelid crease position. 
Table I Means and standard deviations for inner canthi distance according to gender, group, and age group

\begin{tabular}{llllll}
\hline Sex & Group & Age group & & & \\
\cline { 3 - 6 } & & $\mathbf{2 0}$ to $\mathbf{2 9}$ years & $\mathbf{3 0}$ to $\mathbf{3 9}$ years & $\mathbf{4 0}$ to $\mathbf{4 9}$ years & $\mathbf{2}$ years \\
\hline Male & Nikkeis & $37.47 \pm 2.99^{*}$ & $34.94 \pm 3.27$ & $36.07 \pm 2.84^{*}$ & $35.99 \pm 3.4 I^{*}$ \\
& Japanese & $38.85 \pm 3.13^{*}$ & $36.16 \pm 2.38$ & $38.15 \pm 2.78^{*}$ & $37.09 \pm 3.43^{*}$ \\
\multirow{2}{*}{ Female } & Nikkeis & $34.99 \pm 3.03$ & $33.76 \pm 2.97$ & $33.90 \pm 2.45$ & $32.74 \pm 2.71$ \\
& Japanese & $35.72 \pm 3.04$ & $34.43 \pm 2.52$ & $35.39 \pm 2.39$ & $34.56 \pm 2.79$ \\
\hline
\end{tabular}

Notes: $*(p<0.05)$ for male vs. female fixed, group, and age group.

Horizontal fissure values were barely higher in the Japanese, with statistical significance for Japanese women from 20 to 29 years, and Japanese men from 40 to 49 years. Comparing individuals within age groups, Japanese women over 50 years had much lower values than the rest (Table 3).

Vertical fissure distance was larger in younger Japanese. Female Nikkeis also demonstrated greater values than male Nikkeis. Comparing age groups, the smallest vertical fissure dimensions were found in the over 50's (Table 4).

MRD dimensions were similar in both populations, but there was a tendency for higher values in Japanese; the only significant difference was in female Nikkeis who had larger dimensions than their Japanese counterparts. MRD also tended to be less in the elderly (Table 5).

Upper eyelid crease dimensions showed no statistical significance between group; however, Japanese women always had discretely higher values (Table 6).

Palpebral fissure area tended to be higher in the Japanese group and in men. Measurements in the individuals over 50 years old were significantly smaller (Table 7 ).

Palpebral fissure obliquity was more accentuated in the Japanese population at all ages. Values also tended to be higher in women. Comparison between age groups showed lower values as long as age advanced (Table 8).

\section{Discussion}

The shape and characteristics of the palpebral fissure are influenced by race, as has been documented in several racial comparative studies (Iosub et al 1985; Leung et al 1990;
Kaimbo and Kaimbo 1995; Jeong et al 1999; Hanada et al 2001). In the present study we evaluated members of the oriental race living in different localities, and who were therefore submitted to distinct exogenous factors.

Both populations consisted of similar numbers from both sexes and were divided into age groups to check for gender and age related differences (Lam et al 1995; Siqueira et al 2005). Differences between the Nikkeis and Japanese were very subtle, and frequently without significantly statistical difference.

Distances between inner canthi and pupils tended to be higher in the Japanese, and in men rather than women. For horizontal and vertical fissure, mean values were higher in the Japanese. A reduction in palpebral fissure width was found mainly in women (in the group older than 50 years old); this has already been explored in literature (van den Bosch et al 1999; Siqueira et al 2005) and can be attributed to disinsertion and slackness of the palpebral structures which occur at individuals of advanced ages (Nesi et al 1997).

Mean MRD values were higher in Japanese than Nikkeis in nearly all age groups, but differences were not statistically significant. As a consequence of lower vertical fissure values, mean MRD values were also lower in more elderly individuals.

In relation to crease height, differences were small and variability high; this meant that it was necessary to use medians and inter-quartile amplitude with this parameter. It is known that the Oriental eyelid has a much lower superior palpebral crease position than a Caucasian one, and it can even be absent

Table 2 Means and standard deviations for distance between pupils according to gender, group and age group

\begin{tabular}{llllll}
\hline Sex & Group & Age group & & \\
\cline { 3 - 6 } & & $\mathbf{2 0}$ to $\mathbf{2 9}$ years & $\mathbf{3 0}$ to $\mathbf{3 9}$ years & $\mathbf{4 0}$ to $\mathbf{4 9}$ years & $\mathbf{3 0}$ years \\
\hline Male & Nikkeis & $61.08 \pm 4.13^{*}$ & $61.36 \pm 3.64^{*}$ & $60.86 \pm 3.90$ & $60.50 \pm 2.64^{*}$ \\
& Japanese & $63.07 \pm 3.15^{*}$ & $62.32 \pm 3.67^{*}$ & $66.31 \pm 3.21^{\mathbf{*} *}$ & $61.05 \pm 4.76^{*}$ \\
Female & Nikkeis & $57.14 \pm 3.17$ & $58.19 \pm 3.23$ & $59.70 \pm 3.43$ & $55.98 \pm 3.62$ \\
& Japanese & $60.20 \pm 3.88^{\star}$ & $59.41 \pm 3.38$ & $59.41 \pm 2.40$ & $57.39 \pm 3.43$ \\
\hline
\end{tabular}

Notes: ${ }^{\wedge}(p<0.05)$ : indicates significant Nikkeis vs. Japanese comparison for fixed, gender, and age group; $*(p<0.05)$ : indicates significant male vs. female comparison for fixed, group, and age group; ${ }^{*}(\mathrm{p}<0.05)$ : indicates significant comparison between age groups, fixed, group, and gender. 
Table 3 Means and standard deviations for horizontal fissure according to gender, group, and age group

\begin{tabular}{|c|c|c|c|c|c|}
\hline \multirow[t]{2}{*}{ Sex } & \multirow[t]{2}{*}{ Group } & \multicolumn{4}{|l|}{ Age group } \\
\hline & & 20 to 29 years & 30 to 39 years & 40 to 49 years & $\geq \mathbf{5 0}$ years \\
\hline \multirow[t]{2}{*}{ Male } & Nikkeis & $24.87 \pm 1.84$ & $25.54 \pm 1.65$ & $24.89 \pm|.5|$ & $23.41 \pm 1.85$ \\
\hline & Japanese & $25.21 \pm 1.27$ & $25.72 \pm 1.73$ & $27.26 \pm 1.12^{\star *} *$ & $23.14 \pm 2.51$ \\
\hline \multirow[t]{2}{*}{ Female } & Nikkeis & $23.63 \pm 1.37$ & $24.22 \pm 1.72$ & $25.10 \pm 1.82$ & $22.78 \pm 1.86$ \\
\hline & Japanese & $24.99 \pm 1.68^{\Delta \#}$ & $24.63 \pm 1.42^{\#}$ & $24.26 \pm 1.40^{\#}$ & $22.52 \pm 2.11$ \\
\hline
\end{tabular}

Notes: ${ }^{\wedge}(p<0.05)$ : indicates significant Nikkeis vs. Japanese comparison for fixed, gender, and age group; ${ }^{*}(p<0.05)$ : indicates significant male vs. female comparison for fixed, group, and age group; ${ }^{*}(\mathrm{p}<0.05)$ : indicates significant comparison between age groups, fixed, group, and gender.

Table 4 Means and standard deviations for vertical fissure according to gender, group, and age group

\begin{tabular}{llllll}
\hline Sex & Group & Age group & & \\
\cline { 3 - 6 } & & $\mathbf{2 0}$ to $\mathbf{2 9}$ years & $\mathbf{3 0}$ to $\mathbf{3 9}$ years & $\mathbf{4 0}$ to $\mathbf{4 9}$ years & $\geq \mathbf{5 0}$ years \\
\hline Male & Nikkeis & $6.86 \pm 2.80$ & $7.98 \pm 1.59^{\#}$ & $8.87 \pm 1.68^{\#}$ & $7.58 \pm 1.23^{\#}$ \\
& Japanese & $9.23 \pm 0.96^{\star \#}$ & $9.06 \pm 1.80^{\star \#}$ & $9.10 \pm 0.92^{\#}$ & $7.32 \pm 1.33$ \\
Female & Nikkeis & $8.84 \pm 1.1^{*}$ & $8.34 \pm 1.17$ & $8.95 \pm 1.08$ & $8.51 \pm 0.83$ \\
& Japanese & $9.10 \pm 1.65^{\#}$ & $9.08 \pm 1.74^{\#}$ & $8.65 \pm 1.1 I^{\#}$ & $7.33 \pm 1.29$ \\
\hline
\end{tabular}

Notes: ${ }^{\wedge}(p<0.05)$ for Nikkeis vs. Japanese, fixed, gender, and age group; ${ }^{*}(p<0.05)$ for male vs female fixed group, and age group; ${ }^{*}(p<0.05)$ for $(F 1, F 2$, and F3) vs. F4 and (F2, F3, and F4) vs. FI fixed gender and group.

Table 5 Means and standard deviations for MRD according to gender, group, and age group

\begin{tabular}{llllll}
\hline Sex & Group & Age group & & \\
\cline { 3 - 6 } & & $\mathbf{2 0}$ to $\mathbf{2 9}$ years & $\mathbf{3 0}$ to $\mathbf{3 9}$ years & $\mathbf{4 0}$ to $\mathbf{4 9}$ years & $\mathbf{2} \mathbf{5 0}$ years \\
\hline Male & Nikkeis & $2.63 \pm 1.10$ & $2.76 \pm 1.05$ & $3.10 \pm 1.40$ & $2.40 \pm 0.77$ \\
& Japanese & $3.12 \pm 0.90$ & $3.13 \pm 1.16$ & $3.23 \pm 0.81$ & $2.75 \pm 0.85$ \\
Female & Nikkeis & $3.11 \pm 0.94$ & $2.90 \pm 0.72$ & $2.85 \pm 0.72$ & $3.52 \pm 0.57^{\mathbf{4}}$ \\
& Japanese & $3.12 \pm 0.90$ & $3.53 \pm 1.05$ & $3.39 \pm 0.84$ & $2.62 \pm 0.77$ \\
\hline
\end{tabular}

Notes: ${ }^{\star}(p<0.05)$ for Nikkeis $x$ Japanese, fixed, gender, and age group.

Abbreviation: MRD, distance between the superior lid margin and corneal reflexes.

Table 6 Median and total semi-amplitude for crease position according to gender, group, and age group

\begin{tabular}{llllll}
\hline Sex & Group & Age group & & \\
\cline { 3 - 6 } & & $\mathbf{2 0}$ to $\mathbf{2 9}$ years & $\mathbf{3 0}$ to $\mathbf{3 9}$ years & $\mathbf{4 0}$ to $\mathbf{4 9}$ years & $\mathbf{2} \mathbf{5 0}$ years \\
\hline Male & Nikkeis & $0.32 \pm 0.92$ & $1.25 \pm 1.59$ & $0.00 \pm 1.83$ & $0.20 \pm 2.20$ \\
& Japanese & $0.00 \pm 1.55$ & $0.00 \pm 2.39$ & $1.51 \pm 2.20$ & $1.14 \pm 2.07$ \\
Female & Nikkeis & $0.91 \pm 1.64$ & $0.00 \pm 1.75$ & $1.76 \pm 2.10$ & $0.71 \pm 1.41$ \\
& Japanese & $1.96 \pm 3.54$ & $1.41 \pm 1.83$ & $1.92 \pm 2.24$ & $1.43 \pm 1.90$ \\
\hline
\end{tabular}

Table 7 Means and standard deviations for fissure area according to gender, group, and age group

\begin{tabular}{llllll}
\hline Sex & Group & Age group & & & \\
\cline { 3 - 6 } & & $\mathbf{2 0}$ to $\mathbf{2 9}$ years & $\mathbf{3 0}$ to $\mathbf{3 9}$ years & $\mathbf{4 0}$ to $\mathbf{4 9}$ years & $\geq \mathbf{5 0}$ years \\
\hline Male & Nikkeis & $150.82 \pm 27.06$ & $138.71 \pm 35.14$ & $153.27 \pm 37.99$ & $124.18 \pm 28.29$ \\
& Japanese & $167.83 \pm 19.83^{\#}$ & $169.62 \pm 41.33^{\text {\#\# }}$ & $170.50 \pm 22.97^{\#}$ & $118.13 \pm 28.55$ \\
Female & Nikkeis & $153.42 \pm 25.70$ & $144.67 \pm 24.88$ & $149.93 \pm 22.75$ & $132.31 \pm 19.28$ \\
& Japanese & $160.85 \pm 38.10^{\#}$ & $160.16 \pm 37.18^{\#}$ & $148.13 \pm 26.49^{\#}$ & $113.12 \pm 28.46$ \\
\hline
\end{tabular}

Notes: ${ }^{\wedge}(p<0.05)$ for Nikkeis vs. Japanese, fixed, gender, and age group; ${ }^{\sharp}(p<0.05)(F I, F 2$, and F3) vs. F4 fixed, gender, and group. 
Table 8 Means and standard deviation for fissure obliquity according to gender, group, and age group

\begin{tabular}{llllll}
\hline Sex & Group & Age group & & \\
\cline { 3 - 6 } & & $\mathbf{2 0}$ to $\mathbf{2 9}$ years & $\mathbf{3 0}$ to $\mathbf{3 9}$ years & $\mathbf{4 0}$ to $\mathbf{4 9}$ years & $\geq \mathbf{5 0}$ years \\
\hline Male & Nikkeis & $7.13 \pm 3.63^{\#}$ & $4.51 \pm 1.41$ & $4.93 \pm 0.84$ & $3.23 \pm 1.90$ \\
& Japanese & $6.62 \pm 1.73$ & $6.79 \pm 2.49^{\star}$ & $5.27 \pm 2.86$ & $6.68 \pm 2.09^{\star}$ \\
Female & Nikkeis & $6.11 \pm 3.41$ & $5.52 \pm 1.62$ & $5.06 \pm 2.51$ & $4.72 \pm 1.64$ \\
& Japanese & $7.80 \pm 3.18$ & $6.71 \pm 2.19^{\star}$ & $6.02 \pm 2.37$ & $6.74 \pm 1.52^{\star}$ \\
\hline
\end{tabular}

Notes: ${ }^{\star}(p<0.05)$ for Nikkeis vs. Japanese, fixed, gender, and age group; ${ }^{*}(p<0.05)$ for (F2, F3, and F4) vs. FI fixed, gender, and group.

due to particular anatomical differences. It should be noted that the Japanese often use adhesive to artificially shape the upper eyelid crease, which can often remain even after discontinuing the treatment, and could explain their discreet larger values.

Evaluation of palpebral fissure area reflects other studied parameters. Discreet higher values in fissure width and height and MRD seen in Japanese lead to their higher palpebral fissure areas. The oldest population had lower values for this parameter, which certainly link it with senility, when smaller vertical and horizontal palpebral fissures cause smaller palpebral fissure area. However, when analyzed apart this did not have the same tendencies as MRD or vertical and horizontal fissures. The palpebral fissure has a three-dimensional surface mainly shaped by the eyeball which pushes out and moulds both eyelid and all palpebral shape, including apexes and depressions, and the parabolic line of the superior lid, influencing the shape of the palpebral fissure (Maulboisson et al 2000).

Palpebral fissure obliquity is more accentuated in Japanese groups. Evaluation of fissure obliquity in Caucasians, Japanese and descendents, and Brazilian Indians shows mean inclinations of $4.60^{\circ}, 9.39^{\circ}$, and $9.34^{\circ}$, respectively (Hanada et al 2001). In this study, both groups had superior mean values $\left(5.15^{\circ}\right.$ in Nikkeis and $6.57^{\circ}$ in Japanese) to the Caucasian population, but less than Orientals from a previous study (Hanada et al 2001). This may have been due to the methodology used in evaluating inclination.

\section{Conclusion}

These results allow us to conclude that there are few differences in eyelids between Orientals and the Nikkeis who are living in Brazil. Environmental factors were not sufficiently strong to change the genetic load which has determined the shape of the oriental lids until the present.

\section{Acknowledgments}

JICA (Japan International Cooperation Agency) and the Hamamatsu Seirei General Hospital. The authors report no conflict of interest.

\section{References}

Doxanas MT, Anderson RL. 1984. Oriental eyelids - an anatomic study. Arch Ophthalmol, 102:1232-35.

Hanada AL, Junior EN, Moribe I, et al. 2001. Comparison of palpebral fissure obliquity in three different racial groups. Ophthal Plast Reconstr Surg, 17:423-26.

Iosub S, Fuchs M, Bingol N, et al.1985. Palpebral fissure length in black and Hispanic children: correlation with head circumference. Pediatrics, 75:318-20.

Jeong S, Lemke BN, Dortzbach RK, et al. 1999. The Asian upper eyelid: an anatomical study with comparison to the Caucasian eyelid. Arch Ophthalmol, 117:907-12.

Kaimbo WA, Kaimbo D.1995. Palpebral measurements in healthy subjects in Zaire. J Fr Ophtalmol, 18:286-91.

Lam BL, Lam S, Walls RC. 1995. Prevalence of palpebral fissure asymmetry in white persons. Am J Ophthalmol, 120:518-22.

Leung AK, Ma KC, Siu TO, et al.1990. Palpebral fissure length in Chinese newborn infants. Comparison with other ethnic groups. Clin Pediatr, 29:172-4.

Malbouisson JM, Baccega A, Cruz AAV. 2000. The geometrical basis of the eyelid contour. Ophthal Plast Reconstr Surg, 16:427-31.

Nesi FA, Lisman RD, Levine MR. 1997. Ophthalmic plastic and reconstructive surgery. 2th ed. St Louis: Mosby.

Siqueira M, Joaquim A, Schellini SA, et al. 2005. Alterações palpebrais após a idade de 50 anos. Arq Bras Oftalmol, 68:285-90.

van den Bosch WA, Leenders I, Mulder P. 1999. Topographic anatomy of the eyelids, and the effects of sex and age. Br J Ophthalmol, 83:347-52. 
